\title{
Bone-marrow derived cells participate in extramedullary hematopoiesis in a model of acetaminophen-induced acute liver failure in rats
}

\author{
Maria Cristina Belardinelli ${ }^{1}$, Mónica López ${ }^{1,2}$, Talita Giacomet de Carvalhoo ${ }^{1,2}$, Fabiana Mayer ${ }^{1,2}$, \\ Guilherme Baldo $^{1,3}$, Luise Meurer ${ }^{4}$, Roberto Giugliani ${ }^{1,2,3}$, Ursula Matte $^{1,2^{\star}}$ \\ ${ }^{1}$ Gene Therapy Center, Research Center of Hospital de Clinicas de Porto Alegre, Porto Alegre, Brazil; \\ *Corresponding Author: umatte@hcpa.ufrgs.br \\ ${ }^{2}$ Post Graduation Program in Genetics and Molecular Biology, UFRGS, Porto Alegre, Brazil \\ ${ }^{3}$ Post Graduation Program in Sciences: Biochemistry, UFRGS, Porto Alegre, Brazil \\ ${ }^{4}$ Pathology Service of Hospital de Clinicas de Porto Alegre, Porto Alegre, Brazil
}

Received 23 October 2012; revised 25 November 2012; accepted 28 December 2012

\begin{abstract}
Adult derived mononuclear bone marrow cells are a good alternative as cell therapy. These cells are capable of significantly improve survival rate of Wistar rats with acetaminophen (APAP) induced acute liver failure in ten days. However, long term of cell therapy is not deeply studied in the literature. Here, we report an extramedullary hematopoiesis process derived from transplanted mononuclear bone marrow cells in the liver of rats 10 days after APAP injection. This result indicates that liver maintains an adequate microenvironment for the occurrence of extramedullary hematopoiesis process. The consequence of this finding deserves more studies.
\end{abstract}

Keywords: Extramedullary Hematopoiesis; Bone Marrow Cells; Acute Liver Failure; Acetaminophen

\section{INTRODUCTION}

Acute liver failure (ALF) is characterized by a rapid loss of hepatic function, with high mortality [1]. Acetaminophen (APAP) intoxication is one of the mainly causes of ALF [2]. Therapeutic doses ( $>90 \%)$ of APAP are glucuronidated or sulfated and then excreted [3]. A small percentage is metabolized by cytochrome $\mathrm{P} 450$ enzymes (CYP) to the reactive intermediate N-acetyl-pbenzoquinone imine (NAPQI), which is detoxified by conjugation with glutathione (GSH) [4]. Overdoses of APAP lead to high levels of NAPQI, causing cell necrosis by abrogation of calcium influx to the mitochondria [3,5]. Several studies have shown the capacity of adult bone marrow cells in liver repair, suggesting their use for treating ALF [6,7]. These cells may participate in liver regeneration via proliferation and transdifferentiation into hepatocytes [7]. Also, some groups have proposed a paracrine effect that enhances hepatocyte proliferation $[6$, 8].

In a previous work we have shown the capacity of adult derived mononuclear bone marrow cells to improve the survival of Wistar rats with acetaminophen (APAP)induced acute liver failure (ALF) [8]. The underlying mechanism probably involves paracrine effects of bone marrow cells that stimulate hepatocyte proliferation in the regenerating liver [6]. Beneficial aspects of bone marrow derived cells have been reported in different conditions [9]. However, long term and safety effects of cell therapy are not well explored in the literature. Here we report the unexpected finding of bone marrow derived extramedullary hematopoiesis in the liver of rats that survived for 10 days after APAP injection.

\section{MATERIALS AND METHODS}

\subsection{Animal Model}

Experimental procedures were similar to those described in Bellardinelli et al. (2008) [8]. Briefly, female Wistar rats $(\mathrm{n}=9)$ were pre-induced with phenobarbital (Aventis $^{\circledR}$, Brazil $)(0.4 \mathrm{~g} / \mathrm{L}$, or approximately $0.1 \mathrm{mg} / \mathrm{kg}$ body weight) in drinking water. After four days, the animals were given APAP $\left(\right.$ Medley $^{\circledR}$, Brazil) in a single dose of 1 $\mathrm{g} / \mathrm{kg}$ via intraperitoneal injection. This work was approved by the Research Ethics Committee of Hospital de Clínicas de Porto Alegre.

\subsection{Mononuclear Cell Therapy}

Twenty four hours after APAP-induced ALF, animals were anesthetized with $100 \mathrm{mg} / \mathrm{kg}$ of Ketamine (Euro- 
farma Lab LTDA, SP, Brazil) $10 \%$ and $10 \mathrm{mg} / \mathrm{kg}$ of Xylazine (Sespo Ind and Com LTDA, SP, Brazil) 2\% intraperitoneally, and a longitudinal abdominal incision was performed to inject the bone marrow mononuclear cells (BMMC).

Whole bone marrow cells were obtained from male donor rats by flushing the femur and tibia with Dulbecco's modified eagle's medium (DMEM, Invitrogen, USA) and bone marrow mononuclear cells were purified using FICOLL (GE-Healthcare, USA) gradient. BMMC were injected through the exposed portal vein in a volume of $0.2 \mathrm{~mL}$ containing $1 \times 10^{6}$ cells. The APAP-induced ALF rats were kept for 10 days after BMMC injection, and then euthanized in a $\mathrm{CO}_{2}$ chamber.

\subsection{Histology and DNA Processing}

Immediately after sacrificed of rats, the liver was collected, placed in $10 \%$ buffered formalin solution for $24 \mathrm{~h}$, and submitted to routine histology processing. H-E staining sections were analyzed under optic microscopy by a trained pathologist. To confirm donor-derived origin, recipient female liver samples were screened for the presence of the Y-chromosome gene Sry by PCR. For that, paraffin-embedded tissue was microdissected under inverse microscope. DNA was extracted from $20 \mu \mathrm{m}$ sections as described by Coura et al. (2005) [10] using UltraClean Blood DNA Isolation (MoBio, USA), according to the manufacturer's instructions. DNA was quantified using Nanodrop (Thermo Scientific, USA) and $100 \mathrm{ng}$ were used as template. The Sry gene was amplified using 20 pmol of each primer (SRY forward 5'-AAGCGCCC CATGAATGCATT-3' and SRY reverse 5'-CAGCTGCT TGCTGATCTCTG-3'), $5 \mu \mathrm{l}$ of buffer (75 mM Tris$\mathrm{HCl}-\mathrm{pH} 9.0 ; 2 \mathrm{mM} \mathrm{MgCl}$; $50 \mathrm{mM} \mathrm{KCl}, 20 \mathrm{mM}, 107$ $\left(\mathrm{NH}_{4}\right)_{2} \mathrm{SO}_{4} ; 0.001 \%$ BSA); $0.2 \mathrm{mM}$ dNTP; $1.5 \mathrm{mM}$ of $\mathrm{MgCl}_{2}$ and $3 \mathrm{U}$ of Taq DNA polymerase. Annealing temperature was $62^{\circ} \mathrm{C}$, and amplification was performed using 32 PCR cycles. A PCR product of 102 bp was visualized in $1.6 \%$ agarose gel.

\section{RESULTS}

All but two animals (that died on day 6) survived for 10 days. Liver histology showed a recovery in the tissue, with many cells still proliferating after 10 days (Figure 1(A)). Moreover, in the H-E slides, clusters of cells were observed near the vessels (Figure 1(B)) in 4 animals. The cells showed blast cell morphology such as small size, large and acentric nuclei, and scant cytoplasm. To elucidate the origin of these cells, a micro-dissection of this area was performed for DNA extraction. PCR for Sry gene was positive (Figure 2), confirming that these cells derived from the male bone marrow donors.
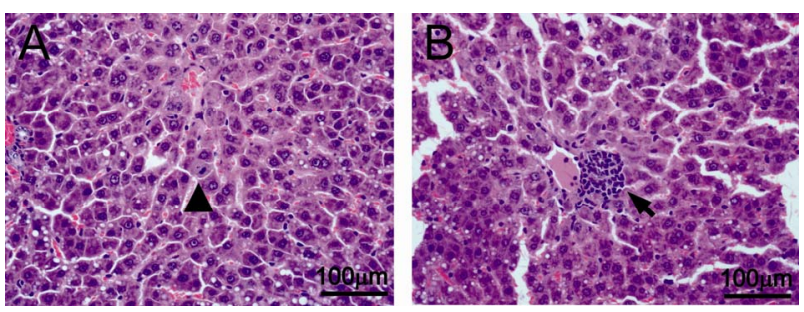

Figure 1. Hematoxilin-Eosin slides from liver sections 10 days after APAP injection in animals that received BMMC. (A) Hepatocyte proliferation (arrow head); (B) Focus of extramedullary hematopoiesis (arrow).

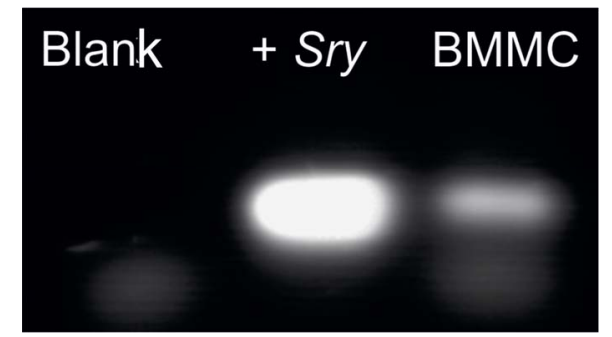

Figure 2. PCR analysis of Sry gene in the microdissected area presented in figure 1-B. Lane 1-blank; lane 2-positive control (male liver); lane 3-female liver that received BMMC.

\section{DISCUSSION}

In adults, extramedullary hematopoiesis is known to take place in the liver when the function of bone marrow is severely suppressed [11]. There are case reports on severe adverse reactions in the bone marrow caused by APAP ingestion. Some are related to overdosis [12] or drug combinations $[13,14]$. Transient effects of DNA synthesis inhibition have been reported, but they seem to resolve in four hours [15]. In our study, no systemic adverse events, such as bleeding or fatigue, were observed.

During acute liver injury many soluble factors are secreted that may also play a role in hematopoiesis such as Interleukin 1 and 6 (IL-1, -6) [16]. For instance, IL-1 regulates the various stages of normal hematopoiesis [17]. Recently, had been shown that liver sinusoidal endothelial cells (LSEC) secrete chemokine stromal-derived factor (SDF-1), which regulates the trafficking/ homing of hematopoietic stem cells to the bone marrow or other organs during extramedullary hematopoiesis [18]. This indicates that LSEC microenvironment constitutes an extramedullary niche for hematopoietic stem cells [19].

Also, Kupffer cells together with endothelial cells, fibroblasts and adipocytes form a suitable hematopoietic microenviroment that regulates in vivo and in vitro hematopoiesis. There is evidence that this micro-environment takes place in the periportal domains of the liver [19] as seen in our study (Figure 1(B)). 
In conclusion, the results showed here suggest that BMMC are able to initiate extramedullary hematopoiesis. Interestingly, the liver retains the adequate micro-environment to let the cells mature and differentiate after an injury. The consequences of this finding for cell therapy protocols deserve further investigations.

\section{ACKNOWLEDGEMENTS}

This work received financial support from FIPE/HCPA. MLL and $\mathrm{UM}$ are recipients of $\mathrm{CNPq}$ scholarships.

\section{REFERENCES}

[1] Polson, J. and Lee, W.M. (2005) AASLD position paper: The management of acute liver failure. Hepatology, 41, 1179-1197. doi:10.1002/hep.20703

[2] Lee, W.M., Squires, R.H., Nyberg, S.L., Doo, E. and Hoofnagle, J.H. (2008) Acute liver failure: Summary of a workshop. Hepatology, 47, 1401-1415. doi:10.1002/hep. 22177

[3] Mcgill, M.R., Sharpe, M.R., Williams, C.D., Taha, M., Curry, S.C. and Jaeschke, H. (2012) The mechanism underlying acetaminophen-induced hepatotoxicity in humans and mice involves mitochondrial damage and nuclear DNA fragmentation. The Journal of Clinical Investigation, 122, 1574-1583. doi:10.1172/JCI59755

[4] Nelson, S. (1990) Molecular mechanisms of the hepatotoxicity caused by acetaminophen. Seminars in Liver Disease, 10, 267-278. doi:10.1055/s-2008-1040482

[5] Gujral, J., Knight, T., Farhood, A., Bajt, M. and Jaeschke H. (2000) Mode of cell death after acetaminophen overdose in mice: apoptosis or oncotic necrosis? Toxicological Sciences: An official journal of Society of Toxicology, 67, 322-328.

[6] Baldo, G, Giugliani, R., Uribe, C., Belardinelli, M.C., Duarte, M.E.S., Meurer, L., da Silveira, T.R. and Matte U. (2010) Bone marrow mononuclear cell transplantation improves survival and induces hepatocyte proliferation in rats after $\mathrm{CCl}(4)$ acute liver damage. Digestive diseases and sciences, 55, 3384-3392. doi:10.1007/s10620-010-1195-4

[7] Li, J., Zhang, L., Xin, J., Jiang, L., Zhang, T., Jin, L., Li, J., Zhou, P., Hao, S., Cao, H. and Li L. (2012) Immediate intraportal transplantation of human bone marrow mesenchymal stem cells prevents death from fulminant hepatic failure in pigs. Hepatology, 56, 2-38. doi:10.1002/hep.25722

[8] Belardinelli, M.C., Pereira, F., Baldo, G., Vicente Tavares, A.M., Kieling, C.O., da Silveira, T.R., Meurer, L., Soares Duarte, M.E., Giugliani, R. and Matte, U. (2008) Adult derived mononuclear bone marrow cells improve survival in a model of acetaminophen-induced acute liver failure in rats. Toxicology, 247, 1-5. doi:10.1016/j.tox.2008.01.015

[9] Sant'anna, N.I., Kalil, R.A., Pretto Neto, A.S., Pivatto Júnior, F., Fracasso, J., Sant'anna, J.R., Marques, M., Markoski, M., Prates, P.R. and Nardi, N.B. (2010) Global contractility increment in nonischemic dilated cardiomyopathy after free wall-only intramyocardial injection of autologous bone marrow mononuclear cells: An insight over stem cells clinical mechanism of action. Cell Transplantation, 19, 959-964. doi:10.3727/096368910X514648

[10] Coura, R., Prolla, J., Meurer, L. and Ashton-Prolla, P. (2005) An alternative protocol for DNA extraction from formalin fixed and paraffin wax embedded tissue. Journal of Clinical Pathology, 58, 894-895. doi:10.1136/jep.2004.021352

[11] Otsuka, H., Yagi, H., Endo, Y., Nonaka, N. and Nakamura, M. (2011) Kupffer cells support extramedullary erythropoiesis induced by nitrogen-containing bisphosphonate in splenectomized mice. Cellular Immunology, 271, 197-204. doi:10.1016/j.cellimm.2011.06.025

[12] Gürsoy, M., Haznedaroğlu, I.C., Celik, I., Sayinalp, N., Ozcebe, O.I. (1996) Agranulocytosis, plasmacytosis, and thrombocytosis followed by a leukemoid reaction due to acute acetaminophen toxicity. The Annals of Pharmacotherapy, 30, 762-765.

[13] MacKinnon, H. and Menon, R. (1974) Letter: Reaction to acetaminophen. Canadian Medical Associacion Journal, 8, 1237-1239.

[14] Datta, S. (1973) Fatal pancytopenia after administration of fortagestic. British Medical Journal, 21,173. doi:10.1136/bmj.3.5872.173-c

[15] Lister, C. and McLean, A. (1997) Inhibition of DNA synthesis by paracetamol in different tissues of the rat in vivo. Toxicology, 15, 49-57. doi:10.1016/S0300-483X(96)03521-4

[16] Michalopoulos, G.K. (2007) Liver regeneration. Journal of Cell Physiology, 213, 286-300. doi:10.1002/jcp.21172

[17] Bodo, M., Baroni, T. and Tabilio, A. (2009) Haematopoietic and stromal stem cell regulation by extracellular matrix components and growth factors. Journal of Stem Cells, 4, 57-69.

[18] Mendt, M. and Cardier, J.E. (2012) Stromal-derived factor- 1 and its receptor, cxcr4, are constitutively expressed by mouse liver sinusoidal endothelial cells: Implications for the regulation of hematopoietic cell migration to the liver during extramedullary hematopoiesis. Stem Cells and Development, 21, 2142-2151. doi:10.1089/scd.2011.0565

[19] Cardier, J.E. and Barberá-Guillem, E. (1997) Extramedullary hematopoiesis in the adult mouse liver is associated with specific hepatic sinusoidal endothelial cells. Hepatology, 26, 165-175. doi:10.1002/hep.510260122 